\title{
A COMPARISON BETWEEN INTRAVENOUS PARACETAMOL PLUS INTRAVENOUS FENTANYL AND INTRAVENOUS FENTANYL PLUS INTRAVENOUS KETOROLAC FOR POSTOPERATIVE ANALGESIA DURING LAPAROSCOPIC CHOLECYSTECTOMY
}

\author{
Sheikh Abdul Mannan ${ }^{1}$, Basharat Ahad ${ }^{2}$, Rabiaarifa ${ }^{3}$ \\ ${ }^{1}$ Assistant Professor, Department of Anaesthesiology, SKIMS Medical College, Bemina. \\ ${ }^{2}$ Associate Professor, Department of Anaesthesiology, SKIMS Medical College, Bemina. \\ 3Medical Officer, JK Health Services.
}

\section{ABSTRACT}

\section{BACKGROUND}

Studies have suggested a large inter-individual variation in postoperative pain after laparoscopic cholecystectomy, emphasising the need for improved analgesic treatment and valid predictors. Our study compared the effect of fentanyl plus intravenous paracetamol with fentanyl plus intravenous ketorolac for analgesic efficacy, opioid sparing effects and opioid-related side effects after laparoscopic cholecystectomy.

\section{MATERIALS AND METHODS}

Sixty patients undergoing laparoscopic cholecystectomy were randomised into two groups. Both groups received fentanyl during induction. First group of patients received IV injection of $1 \mathrm{~g}$ paracetamol 15 minutes before the end of surgery, while second group received $0.5 \mathrm{mg} / \mathrm{kg}$ of IV ketorolac 15 minutes before the end of surgery. The postoperative pain relief was evaluated by a Visual Analog Scale (VAS) using a 100-mm visual analog scale, adverse effects as well as vital signs were recorded every 15 mins for 150 mins or until discharge from the post-anaesthesia care unit.

\section{RESULTS}

The mean VAS score after surgery was less in the group receiving IV ketorolac than receiving IV paracetamol at most of the times, but it was statistically non-significant. The rescue analgesia consumption over first $24 \mathrm{~h}$ was also less in the group receiving IV ketorolac ( $40 \pm 25.9$ vs. $57 \pm 20.1$ ), but it was also statistically non-significant. The time requirement of first dose of rescue analgesic in the postoperative period was prolonged in the group receiving IV ketorolac $(240 \pm 24.9)$ than in the group receiving IV paracetamol $(170 \pm 18.8)$. There was no difference in the sedation scores and in the incidence of PONV in the two groups.

\section{CONCLUSION}

The study demonstrates the usefulness of both intravenous ketorolac and paracetamol as supplementary analgesic in the treatment of postoperative pain after laparoscopic cholecystectomy.

\section{KEYWORDS}

Paracetamol (PCM), Intravenous Ketorolac, Pain after Laparoscopic Cholecystectomy, Postoperative Analgesia.

HOW TO CITE THIS ARTICLE: Mannan SA, Ahad B, Rabiaarifa. A comparison between intravenous paracetamol plus intravenous fentanyl and intravenous fentanyl plus intravenous ketorolac for postoperative analgesia during laparoscopic cholecystectomy. J. Evolution Med. Dent. Sci. 2017;6(67):4815-4818, DOI: 10.14260/Jemds/2017/1044

\section{BACKGROUND}

The International Association for the Study of Pain defines pain as "an unpleasant sensory and emotional experience associated with actual or potential tissue damage or described in terms of such damage."1 Pain is the most common complaint after laparoscopic cholecystectomy 2,3 resulting in the use of rescue opioid analgesics in up to $80 \%$ patients. ${ }^{4}$ Furthermore, the pattern of pain after laparoscopic cholecystectomy is complex and unlikely to benefit always from identical analgesic treatment. ${ }^{5}$

Acetaminophen (paracetamol) is an analgesic and antipyretic medication that produces its analgesic effect by inhibiting central prostaglandin synthesis with minimal inhibition of peripheral prostaglandin synthesis. 6,7

Financial or Other, Competing Interest: None.

Submission 11-07-2017, Peer Review 10-08-2017,

Acceptance 16-08-2017, Published 21-08-2017.

Corresponding Author:

Sheikh Abdul Mannan,

Assistant Professor,

Department of Anaesthesiology,

SKIMS Medical College, Bemina.

E-mail: medicalacademy@rediffmail.com

DOI: $10.14260 /$ jemds $/ 2017 / 1044$
A small portion of acetaminophen is bound to plasma proteins $(10 \%-50 \%)$ and has an estimated volume of distribution of $0.95 \mathrm{~L} / \mathrm{kg}$. Acetaminophen is eliminated from the body primarily by formation of glucuronide and sulphate conjugates in a dose-dependent manner. The half-life of acetaminophen is approximately 2 to $3 \mathrm{~h}$ in healthy subjects.

Ketorolac or ketorolac tromethamine is a non-steroidal anti-inflammatory drug (NSAID) in the family of heterocyclic acetic acid derivatives that inhibits both cyclo-oxygenase and lipoxygenase enzymes, thereby preventing the synthesis of both prostaglandins and leukotrienes ${ }^{8}$ and may also release endogenous opioids. ${ }^{9}$ Ketorolac is highly bound to plasma proteins and has an estimated volume of distribution of 0.28 $\mathrm{L} / \mathrm{kg}$. Ketorolac is excreted primarily in the urine and has a half-life of approximately 5 to $6 \mathrm{~h}$ in healthy subjects.

The aim of this randomised study was to compare the analgesic efficacy of intravenous fentanyl with paracetamol versus intravenous fentanyl plus ketorolac for postoperative pain relief after laparoscopic cholecystectomy.

\section{MATERIALS AND METHODS}

After informed consent, a total of 60 patients of either sex weighing between 56 - $80 \mathrm{~kg}$ and age between $30-60$ years 
belonging to ASA-I and ASA-II presenting for elective laparoscopic cholecystectomy were included in the study. The sample size was 60 for our convenience. The study was done between March 2017 and May 2017. Patients with diagnostic laparoscopy, those having contraindications to Ketorolac and paracetamol or to non-steroidal antiinflammatory drugs (NSAIDs) (oesophagogastroduodenal disease, renal insufficiency and abnormal coagulation) were excluded, as were those on treatment by steroids, NSAIDs or opioids before surgery.

\section{The Patients were randomly divided into Two Groups}

Group P: 30 patients in whom fentanyl with paracetamol was used as intravenous analgesia.

Group K: 30 patients in whom fentanyl plus ketorolac was used as an intravenous analgesia.

\section{Methods/Design}

The study design was prospective, randomised, controlled and unblinded. The randomisation was done using Block Randomisation. A block randomisation was done by making blocks of 4 patients each. Patients within the block were assigned numeric values. They were then randomly allocated to Group P and Group K, so that each group was assigned 2 patients. The study was designed to investigate the effectiveness of paracetamol and ketorolac as supplementary analgesia with fentanyl. Patients were premedicated with Tab. Alprazolam $0.25 \mathrm{mg}$ on night before surgery. On arrival to the operating room, after establishing I/V line all standard monitoring techniques were used and crystalloid infusion was started.

After the administration of oxygen, anaesthesia was induced in both the groups with IV propofol $(2 \mathrm{mg} / \mathrm{kg})$, fentanyl $(2 \mu \mathrm{g} / \mathrm{kg})$ and rocuronium $(0.6 \mathrm{mg} / \mathrm{kg})$. Anaesthesia was maintained by $1-2 \%$ isoflurane in nitrous oxide and oxygen (ratio 2:1). The lungs were mechanically ventilated, and ventilation was adjusted to maintain end-expiratory $\mathrm{CO} 2$ between 34 - $36 \mathrm{mmHg}$ depending on the different stages of laparoscopy. Patients in the fentanyl plus paracetamol group (Group P) received $100 \mathrm{~mL}$ of Paracetamol IV (Kabimol 1 gm) 15 minutes before the end of surgery. Patients in the fentanyl plus ketorolac group (Group K) received ketorolac in the dose of $0.5 \mathrm{mg} / \mathrm{kg}$ intraoperatively 15 minutes before the end of surgery. After tracheal extubation, patients were transferred to the PACU. Postoperative pain was assessed using a visual analog scale (VAS; $0 \mathrm{~cm}$ "no pain" and $10 \mathrm{~cm}$ "worst pain imaginable"). Postoperative analgesia was provided routinely to all patients by intramuscular diclofenac at $8 \mathrm{~h}$ interval and intravenous fentanyl $1 \mu \mathrm{g} / \mathrm{kg}$ was administered as rescue analgesic when the VAS score exceeded 3.

The degree of sedation was determined according to a sedation score ranging from 0 to 2 (0-alert, 1 - drowsy but rousable to voice, and 2- very drowsy but rousable to shaking). The VAS scores and sedation scores were assessed at $1,2,4,6,8,12$ and $24 \mathrm{~h}$ after surgery. Total and incremental fentanyl consumption at these times for both the groups was also recorded. If nausea and/or vomiting occurred the same was noted and $8 \mathrm{mg}$ of ondansetron was given intravenously. The number of patients receiving antiemetics and their total dosages were noted. Patients were observed for the occurrence of any adverse effects during the first $24 \mathrm{~h}$. After $24 \mathrm{~h}$, patients were assessed for: (a) Ability to mobilise and dress, (b) Need for any analgesic, and (c) Surgical complication if any. When the patient scored yes on the former and no on the two latter questions, they were assessed ready for discharge from hospital. All measurements were recorded by the anaesthesia resident who was blinded to the study drugs administered.

Finally, all study observations were documented and tabulated. They were analysed statistically and results were recorded.

The statistical analysis of the data was done by using statistic student's t-test for difference of means for quantitative data analysis.

For nominal data, chi-square test $\left(\chi^{2}\right.$-test) and Fisher's exact test were used.

All these tests were two sided and were referred for $\mathrm{p}$ values for their significance. Any p-value less than 0.05 , i.e. ( $p$ $<0.05$ ) were taken to be statistically significant.

The analysis of the data was performed on statistical package for social sciences, Chicago, USA for windows.

\section{RESULTS}

Both groups were similar in regard to age, weight, sex, ASA physical status, duration of anaesthesia and surgery, intraoperative blood loss and the duration of hospital stay [Table 1].

Table 1. Patient data and characteristics (mean \pm SD)

\begin{tabular}{|lcc|}
\hline Variable & Fentanyl Plus PCM & Fentanyl Plus Ketorolac \\
\hline & Group I & Group II \\
\hline & $\mathbf{n}=\mathbf{3 0}$ & $\mathbf{n}=\mathbf{3 0}$ \\
\hline Age (yrs.) & $57 \pm 15.5$ & $59 \pm 12.8$ \\
\hline Weight $(\mathrm{kg})$ & $64 \pm 5.6$ & $62 \pm 7.0$ \\
\hline ASA physical status $(\mathrm{l} / \mathrm{II})$ & $22 / 8$ & $23 / 7$ \\
\hline Sex $(\mathrm{m} / \mathrm{f})$ & $16 / 14$ & $18 / 12$ \\
\hline Duration of anaesthesia $(\mathrm{min})$ & $46 \pm 12.7$ & $45 \pm 32.2$ \\
\hline Intraoperative blood loss $(\mathrm{ml})$ & $47 \pm 12.5$ & $49 \pm 20.5$ \\
\hline Duration of hospital stay (days) & $1.3 \pm 0.5$ & $1.3 \pm 0.6$ \\
\hline
\end{tabular}

None of the patients in either group required additional dose of fentanyl intraoperatively [Table 2].

Table 2. Postoperative pain relief and side effects

\begin{tabular}{|c|c|c|c|}
\hline Variable & Fentanyl plus PCM & Fentanyl plus ketorolac & Significance \\
\hline & Group P & Group K & \\
\hline & $n=30$ & $n=30$ & \\
\hline Intraoperative fentanyl ( $\mu \mathrm{gm})$ & 0 & 0 & NA \\
\hline Amount of fentanyl in PACU & $47 \pm 15.4$ & $40 \pm 25.9$ & NS \\
\hline \multicolumn{4}{|l|}{$(\min )$} \\
\hline Length of stay in PACU ( $\mathrm{min}$ ) & $65 \pm 18.3$ & $67 \pm 13.9$ & NS \\
\hline Incidence of PONV & $1 / 30$ & $1 / 30$ & NS \\
\hline Incidence of sedation & $1 / 30$ & $1 / 30$ & NS \\
\hline Time for ist analgesia (min) & $170 \pm 18.8$ & $240 \pm 24.9$ & $p<0.05$ \\
\hline No. Of patients requiring rescue & $12 / 30$ & $10 / 30$ & NS \\
\hline \multicolumn{4}{|l|}{ Analgesia in post operative period } \\
\hline$p<0.05$ test of significance & & & \\
\hline
\end{tabular}

\section{Post-operative pain relief and side effects}

The mean VAS pain score over the $24 \mathrm{~h}$ period was similar in both the groups; however, the mean VAS scores were at higher values in PCM group but statistically non-significant at most of the times [Table 3]. 
Table 3. VAS Score

\begin{tabular}{|cccc|}
\hline Time (hrs) & \multicolumn{3}{c|}{ VAS score } \\
& $\begin{array}{c}\text { fentanyl plus PCM } \\
\text { Group I } \\
\mathbf{n}=\mathbf{3 0}\end{array}$ & $\begin{array}{c}\text { Group II } \\
\text { fentanyl plus ketorolac }\end{array}$ & Significance \\
1 & $3.5 \pm 0.3$ & $3.4 \pm 0.2$ & \\
2 & $3.6 \pm 0.8$ & $3.3 \pm 0.4$ & NS \\
4 & $3.9 \pm 0.4$ & $3.5 \pm 0.5$ & NS \\
6 & $2.8 \pm 0.9$ & $2.7 \pm 0.9$ & NS \\
8 & $2.8 \pm 0.8$ & $2.9 \pm 0.2$ & NS \\
12 & $2.9 \pm 0.7$ & $2.7 \pm 0.8$ & NS \\
24 & $2.5 \pm 0.8$ & $2.4 \pm 0.9$ & NS \\
\hline
\end{tabular}

Pain scores (mean \pm SD)

The total consumption of fentanyl as rescue analgesic in PACU was similar in both the groups, but the time for the first dose of rescue analgesic in the PACU was significantly lower in Group P over Group K [Table 2].

However, the number of patients requiring rescue analgesic was similar in both the groups [Table 2].

There was no difference in the length of stay in PACU, incidence of PONV and in the incidence of sedation [Table 2].

The sedation scores were similar in both the groups [Table 4]. No postoperative complications were reported from any of the groups.

\begin{tabular}{|ccc|}
\hline Time (hrs) & $\begin{array}{c}\text { fentanyl plus PCM } \\
\text { Group P } \\
\mathbf{n = 3 0}\end{array}$ & $\begin{array}{c}\text { fentanyl plus ketorolac } \\
\text { Group K } \\
\mathbf{n}=\mathbf{3 0}\end{array}$ \\
1 & $1(0-2)$ & $1(0-2)$ \\
2 & $1(0-2)$ & $1(0-2)$ \\
4 & $1(0-2)$ & $0(0-2)$ \\
6 & $0(0-2)$ & $0(0-2)$ \\
8 & $0(0-2)$ & $0(0-2)$ \\
12 & $0(0-2)$ & $0(0-2)$ \\
24 & $0(0-2)$ & $0(0-2)$ \\
\hline
\end{tabular}

\section{DISCUSSION}

Effective postoperative pain relief is fundamental to good quality patient care and is a legitimate therapeutic goal. There is increasing evidence relating to good postoperative analgesia to reduced clinical morbidity. ${ }^{10}$ The aim of postoperative pain relief is to provide subjective comfort in addition to inhibiting trauma-induced nociceptive impulses that induce autonomic and somatic reflex responses to pain. The physiological changes brought about by pain result from activation of both central and peripheral nervous systems. Bradykinin and other peptides produce the pain, tissue oedema and hyperaemia associated with the peripheral inflammatory response. Effective analgesia may modify these responses and may reduce the stress response to surgery, thus reduces anxiety, morbidity, cost and length of hospital stay in the postoperative period.

The overall pain after laparoscopic cholecystectomy is a conglomerate of three different components: incisional pain (somatic pain), visceral pain (deep intra-abdominal pain) and shoulder pain (referred to visceral pain). The complex nature of pain after laparoscopic cholecystectomy suggests that effective analgesic treatment should be multimodal.11,12
Opioid therapy is an integral part of a multidisciplinary approach to acute and chronic pain management. An attempt to optimise the patient's pain management may include concurrently combining opioids with non-opioid adjuvant analgesics (nonsteroidal anti-inflammatory drugs [NSAIDs], acetaminophen, antidepressants, anticonvulsants, etc.), physical therapy, psychological therapy and/or injection therapies. Unlike the opioids the NSAIDs do not demonstrate tolerance, and they often are more effective at controlling certain pain conditions with fewer side effects than the opioids. ${ }^{13}$ They have even demonstrated clear clinical utility in such severe pain states as metastatic spread of cancer to bone usually supplementing rather than replacing the role of opioids. ${ }^{14}$

In one study, 15 it was found that Ketorolac exhibits significant opiate-sparing effects in the immediate postoperative period without introducing additional morbidity to paediatric surgical procedures.

There are evidences to support clinically relevant analgesic effect of paracetamol with additives (Opioids, NSAIDs, etc.) in laparoscopic cholecystectomy. ${ }^{16,17}$

In our study, we used paracetamol and ketorolac with fentanyl during intraoperatively and assessed their supplemental analgesic role for fentanyl during postoperative period. We used intravenous paracetamol $1 \mathrm{gm}$ intraoperatively 15 minutes before the end of surgery in one group and used intravenous ketorolac $0.5 \mathrm{mg} / \mathrm{kg}$ intraoperatively 15 minutes before the end of surgery in second group and assessed their effect on intraoperative analgesic requirement, post-operative analgesic effectiveness, post-operative fentanyl consumption, frequency of sideeffects and hospital stay length. Our study showed that both intravenous ketorolac and intravenous paracetamol exhibits significant opiate-sparing effects in the immediate postoperative period when used as part of multimodal analgesic regime and has significant opioid sparing effect.

It has been reported in previous studies that Ketorolac when used as an adjunct produces a $31 \%-37 \%$ decrease in the morphine requirement during the first $24 \mathrm{~h}$ after surgery.14,15 Our study results are consistent with all previous findings in this regard.

It has also been reported in previous studies that paracetamol when used as an adjunct produces $46 \%$ of sparing effect of morphine. ${ }^{18}$ Our study results are consistent with all previous findings in this regard.

In our study, no differences were observed between the two groups in the adequacy of analgesia as assessed by VAS scores. The median pain scores were lower in the ketorolac group (Group K) at most intervals, but statistically nonsignificant and the time for first analgesic requirement was significantly lower in the fentanyl plus PCM group (Group P).

Clinical studies have also found that $30 \mathrm{mg}$ ketorolac employed alone is just as effective as $1 \mathrm{gm}$ intravenous paracetamol, $75 \mathrm{mg}$ diclofenac or $10 \mathrm{mg}$ morphine. ${ }^{16,17}$ Our study did not find any reduction in the opioid related sideeffects (PONV, sedation, etc.) in the ketorolac group (Group II) as might be expected because of the decrease in total fentanyl dose. This may be because of the lesser number of subjects in our study. Larger studies with adequate power to detect opioid-related side-effects would be able to demonstrate the reduction of dose-dependent side-effects of 
fentanyl such as sedation, respiratory depression, urinary retention or nausea.

Our study demonstrated the additive effect of combining intravenous ketorolac or paracetamol with fentanyl on postoperative analgesia resulting in decreased opioid amount and in slightly improved or similar pain relief. The different sites of action of these drugs in the nervous system may be the cause of better pain relief, whereas the primary mechanism of action responsible for ketorolac's antiinflammatory, antipyretic and analgesic effects is the inhibition of prostaglandin synthesis by competitive blocking of the enzyme cyclooxygenase (COX).

The action of paracetamol at a molecular level is unclear, but could be related to the production of reactive metabolites by the peroxidase function of COX-2 which could deplete glutathione, a cofactor of enzymes such as PGE synthase. In vivo effects of paracetamol are similar to those of the selective cyclooxygenase-2 (COX-2) inhibitors. ${ }^{19}$

The analgesic effect of fentanyl is due to its agonist action in the opioid receptors of the central nervous system. The complimentary analgesic actions of the two drugs make them an important component of multimodal pain therapy.

\section{CONCLUSION}

In conclusion, our study demonstrates the usefulness of both intravenous ketorolac and intravenous paracetamol as supplementary analgesia to fentanyl for the postoperative pain after laparoscopic cholecystectomy. Both intravenous ketorolac and intravenous paracetamol use is associated with a satisfactory analgesia and smaller opioid consumption. This may be beneficial in the management of pain after laparoscopic cholecystectomy in patients prone to opioidrelated complications. Further, we can choose intravenous paracetamol instead of intravenous ketorolac in patients who have deranged renal profile as its effect on kidneys.

\section{Limitations}

Small sample sizes were involved in this study for our convenience. For whole population, a larger randomised controlled study involving various cross section of the patients are needed.

\section{REFERENCES}

[1] Merskey H. Pain terms: a supplementary note. Pain 1982;14:205-6.

[2] McMahon AJ, Russell IT, Ramsay G, et al. Laparoscopic and minilaparotomy cholecystectomy: a randomized trial comparing postoperative pain and pulmonary function. Surgery 1994;115(5):533-9.

[3] Troidl H, Spangenberger W, Langen $R$, et al. Laparoscopic cholecystectomy: technical performance, safety and patient's benefit. Endoscopy 1992;24(4):252-61.

[4] Madsen MR, Jensen KE. Postoperative pain and nausea after laparoscopic cholecystectomy. Surg Laparosc Endosc 1992;2(4):303-5.
[5] Mouton WG, Bessell JR, Otten KT, et al. Pain after laparoscopy. Surg Endosc 1999;13(5):445-8.

[6] Botting RM. Mechanism of action of acetaminophen: Is there a cyclooxygenase 3? Clin Infect Diseases 2000;31(Suppl 5):S202-10.

[7] Vasko MR. Prostaglandin-induced neuropeptide release from spinal cord. Prog Brain Res (Neth) 1995; 104:367-80.

[8] Hyers TM, Tricomi SM, Liao JJ. Inhibition of some human neutrophil functions by the cyclooxygenasene inhibitor ketorolac tromethamine. J Leukoc Biol 1992;51(5):490-5.

[9] Domer F. Characterization of the analgesic activity of ketorolac in mice. Eur J Pharmacol 1990;177(3):12735.

[10] Morran C, McArdle CS. The reduction of postoperative chest infection by prophylactic co-trimoxazole. $\mathrm{Br} \mathrm{J}$ Surg 1980;67(7):464-6.

[11] Bisgaard T, Klarskov B, Rosenberg J, et al. Characteristics and prediction of early pain after laparoscopic cholecystectomy. Pain 2001;90(3):261-9.

[12] Michaloliakou C, Chung F, Sharma S. Preoperative multimodal analgesia facilitates recovery after ambulatory laparoscopic cholecystectomy. Anesth Analg 1996;82(1):44-51.

[13] Parr G, Darekar B, Fletcher A, et al. Joint pain and quality of life: results of a randomized trial. Br J Clin Pharmacol 1989;27(2):235-42.

[14] Eisenberg E, Berkey CS, Carr DB, et al. Efficacy and safety of nonsteroidal antiinflammatory drugs for cancer pain: a meta-analysis. J Clin Oncology 1994;12(12):2756-65.

[15] Carney DE, Nicolette LA, Ratner MH, et al. Ketorolac reduces postoperative narcotic requirements. Presented at the 31st Annual Meeting of the American Pediatric Surgical Association, Orlando, Florida, May 25-29, 2000. Journal of Pediatric Surgery 2001;36(1): 76-9.

[16] Hyllested M, Jones S, Pedersen JL, et al. Comparative effect of Paracetamol, NSAIDs or their combination in post-operative pain management. a qualitative review. Br J Anaesth 2002;88(2):199-214.

[17] Remy C, Marret E, Bonnet F. Effects of acetaminophen on morphine side-effects and consumption after major surgery: meta-analysis of randomized controlled trials. Br J Anaesth 2005;94(4):505-13.

[18] Peduto VA, Ballabio M, Stefanini S. Efficacy of propacetamol in the treatment of postoperative pain. Morphine-sparing effect in orthopedic surgery. Italian Collaborative Group on Propacetamol. Acta Anaesthesiol Scand 1998;42(3):293-8.

[19] Graham GG, Scott KF. Mechanism of action of paracetamol. Am J Ther 2005;12(1):46-55. 